\title{
Research on the Models and Development Strategies of Cross-border E-commerce in China
}

\author{
Dechang Zhao \\ Economic and Management School, Weifang University, Weifang, 261061, \\ China
}

\begin{abstract}
As a new model of cross-border trade, the cross-border e-commerce has achieved rapid development, and has become a new growth point of China's e-commerce market and the new "blue ocean" of the e-commerce industry. At present, the mainstream models of the cross-border e-commerce include the patterns of overseas online shopping, overseas direct mail and overseas warehouse. The problems of logistics, payment and law are still restricting the further development of cross-border e-commerce. This paper analyzes the above problems and puts forward the corresponding countermeasures to provide some references for the relevant researchers.

Keywords:Cross-border E-commerce, E-commerce logistics, overseas warehouse
\end{abstract}

\section{Introduction}

Cross-border e-commerce refers to the business activities of different countries or regions of the transaction through the internet and its related information platform. Cross-border e-commerce is the product of the Internet era, the Internet + foreign trade, the concrete embodiment. Due to the rapid development of information technology, the scale is no longer a decisive factor in foreign trade, multi batch, small batch of foreign trade orders are gradually replacing the traditional large foreign trade transactions. This has injected new impetus to the promotion of trade facilitation and stability: with the continuous release of relevant policy effect, to promote mobile Internet, smart logistics and other related technologies, the cross-border e-commerce industry will be the birth of a new large economic 
chain, to promote domestic industrial restructuring and upgrading, and spawned a series of new economic growth point. Cross border e-commerce is the product of the consumer era, to meet the needs of domestic and foreign consumer groups for higher quality of life. At present, the domestic consumer demand for higher quality, more secure, more diverse products and consumption of economic growth has become increasingly apparent. Cross border e-commerce imports to reduce the number of online transactions in the middle of the flat mode, making the price of overseas products fell. Through the introduction of a large number of quality and quality of overseas goods, to upgrade the industry to accelerate the transformation and upgrading of consumption, and ultimately benefit consumers. At the same time, cross-border e-commerce makes the transaction process flat, which is conducive to overseas suppliers.

\section{Basic patterns of cross-border e-commerce in China}

\subsection{Pattern of overseas online shopping}

Overseas online shopping refers to the activities of our domestic consumers to buy some goods through overseas shopping sites. Overseas online shopping is an application model of small cross-border e-commerce trade. Theyoung people are particularly keen on it. After the financial crisis, the mainland tourists like spring breeze general nourishment and major shopping malls, the reason is that the domestic luxury style and a limited number, on the other hand the foreign counter genuine guarantee. The price is much lower than the mainland. Thus it can be seen that the enthusiasm of mainland Chinese consumers for high-end goods in Europe and the United States, it is not difficult to explain the degree of overseas online shopping. Quality, due to the developed countries in Europe and the United States, the relevant supervisory departments monitor the implementation of more stringent, foreign goods are often better than domestic similar products. As a result of the purchase process is complex, the problem of higher transport costs. It is difficult for clients to enjoy commercial customer service. Only the suitable for milk digital products and watches and other high value commodity, not suitable for low value and the purchase of a small amount of goods in transit period is longer, usually a month. It may cause the product has long been detained and there is no need to pay customs duties of legal or regulatory agencies regulate the transport business of the company, so the goods transport process exists and legal liability risk. Overseas online shopping mode is simple and convenient, making it one of the more popular cross-border e-commerce models.

\subsection{Pattern of overseas direct mail}

With overseas shopping website gradually adding, overseas shopping website has provided Chinese interface and Alipay payment. In this mode, you can visit the sea it without overseas direct mail transfer station, but still involves the weight of items and tariff issues. Amazon's overseas purchase consumers can get a new 
experience and full Chinese by Amazon collection of tariffs, the most popular is the Amazon international logistics. Amazon direct delivery of the United States, stable and reliable distribution of logistics, in the Amazon purchase orders, orders will be issued. From the issue to the service can be divided into three stages, namely, the customs, domestic distribution. Two weeks or so can be served, the fastest available within 3 working days. Most of these models accept payment, so basically the same as domestic online shopping. Because of this kind of model of cross-border e-commerce platform has overseas logistics service, so after shopping overseas logistics platform by the unified arrangement, by sea and air transport, postal and other direct entry transportation, according to the requirements of the customs, through e-commerce platform and customs clearance management system, payment orders, waybill information reporting and, according to the tax rate of imported goods entering the country, to achieve rapid clearance.

\subsection{Pattern of overseas warehouse}

Overseas warehouse modelis the model of the seller who will store the goods to foreign warehouses, when the buyer has the demand. The seller can make a quick response to the first time, timely notification of foreign warehouse delivery, improve the logistics response time. The establishment of overseas positions for several reasons: the expansion of overseas warehouse transportation category, reduce logistics costs, the breakthrough volume, heavy weight, value restrictions, and the cost is cheaper than the international courier; overseas warehouse direct local delivery, shorten the delivery time, and the use of local logistics can query online delivery status, customs clearance and reduce obstacles; can increase the added value for the seller, the seller can remotely control the whole process of goods warehousing logistics, take the initiative to master the logistics management chain; in addition, the overseas warehouse model compared to the bonded commodities increased stocking model. Overseas warehouse management involves the training of local staff and local laws on labor standards and other requirements. Overseas warehouse construction will be a large number of corporate funds, the seller will cause financial and supply chain pressures. The emergence of overseas warehouse, not only broke the weight, volume, value of the restrictions, and its cost is cheaper than international courier. Finally, overseas positions can boost sales. Overseas warehouse to overcome the difficulties of cross-border logistics, improve order conversion rate and attract more consumers to buy.

\section{Development strategies of cross-border e-commerce in China}

\subsection{Promote logistics operation efficiency}

For the development of cross-border e-commerce integration needs, we should introduce the supporting policies from the national level to promote the development of cross-border e-commerce logistics. Cross border e-commerce 
logistics companies are facing the logistics and distribution of the time is too long, other countries, customs, commodity inspection and other issues too much, alone on the operation of enterprises cannot be completely resolved. It should be the introduction of cross-border e-commerce logistics development plan for a long time. We should erect a clear goal of the cross-border e-commerce logistics and transfer the formation of the whole industry and the development of the bureau. We should increase the investment in logistics infrastructure construction, so as to realize the unification of domestic and foreign logistics, improve the distribution ability and supporting level of port logistics. We continuously improve the level of port logistics information, and promote the development of cross-border e-commerce logistics. To strengthen the analysis and development of cross-border e-commerce logistics industry analysis, according to the actual China cooperation and economic development of countries, formulate policy of cross-border e-commerce logistics development forward-looking. There are some problems in the development of international logistics in China and the problems with the foreign logistics system, which leads to the difficulties of international transportation and the development of cross-border e-commerce in China. In this regard, on the one hand we should encourage enterprises restructuring, improve the enterprise's strength and scale, and the expansion of international market. On the other hand, the government should coordinate the relationship between domestic and foreign logistics enterprises, establish the logistics cooperation system and perfect the world logistics network of cross-border e-commerce in China.

\subsection{Strengthen payment security construction}

Payment security is the focus of attention of consumers. At present, the crossborder e-commerce payment transactions in our country is more diverse and flexible, payment security risks, but has high therefore, need to constantly improve the cross-border e-commerce payment system, and strengthening the payment security monitoring. In the improvement of cross-border e-commerce payment system, and strengthen the process of payment security monitoring, needing to fund the development of payment security technology, the technology should be fully demonstrated: to ensure the stability of the payment system. We can prevent network security accidents timely. In addition, under the support of the national government, and then further expand the share of cross-border payment market, a comprehensive upgrade of the core competitiveness of crossborder e-commerce development. In addition, the improvement of cross-border ecommerce payment system, and strengthening the payment security monitoring at the same time, to continue to strengthen supervision of cross-border e-commerce mechanisms, such as cross-border payment system management statistics, and the third party payment report to the state government departments timely and regular cross-border capital transactions. The relevant departments of the state government need to work together to build a cross-border e-commerce information platform. At the same time, multi departments should form mutual 
supervision mechanism to safeguard the legitimate rights and interests of consumers.

\subsection{Improve legal supervision mechanism}

Although China's cross-border e-commerce has begun to take shape and develop rapidly, however, the legal system of China has not been fully established. Whether cross-border electronic commerce adopted bonded import or direct mail mode should now be imported self-disciplined, keep good communication with government departments, actively promote the country to improve the legal system of cross-border e-commerce, maintain and regulate trade order, promote the healthy competition and development within the industry, consciously assume enterprises shoulder the important responsibility in Internet trading in the process of. With the support of the national government, with the support of relevant advanced science and technology, cross-border e-commerce related laws and regulations to keep pace with the times. We actively develop the customs supervision mode of innovation, and strict supervision and inspection. At the same time strengthen the guidance of relevant laws and regulations, as far as possible to avoid cross-border security risks, safeguard the interests of consumers. We want to conduct a scientific market research, and highlight the cross-border ecommerce transactions of the common interests of all parties, the pursuit of the supply of multi interests, and respect for the views and suggestions. We can integrate their constructive opinions and suggestions as the materials of the relevant laws and regulations to enhance the international competitiveness of China's cross-border e-commerce.

\section{Conclusion}

The development of cross-border e-commerce plays a significant role in promoting the transformation of traditional foreign trade, and has far-reaching significance for the steady and sustainable development of import and export trade. Under the policy of "One Belt and One Road", the development prospectof China's cross-border e-commerce is very broad. We believe that China's crossborder e-commerce will usher in leapfrog development after the promotion of logistics construction, payment construction and legal construction

\section{References}

[1]Liu Xiaojun, Zhang Bin, The Study of Collaborative Development of Crossborder E-commerceLogistics in Countries along the Belt and Road, China Business and Market, 30(5), pp. 115-120, 2016.

[2]Zhang Xiaheng, Ma Tianshan, Difficulties and Countermeasuresabout China's Cross-border E-commerce Logistics, Contemporary Economic Management, 37(5), pp. 51-54, 2015. 
[3] Zhou Hong, Du Hui, Study on Competitivity of Cross-border E-commerce Logistics Industry of China Based on Diamond Model, Logistics Technology, 34(9), pp. 4-6, 2015.

[4] Zhang Yanyun, Kang Suyuan, Zhao Fengjiao, Li Guochun, Tianjin Science and Technology, 43(8), pp. 1-2+5, 2016. 